\title{
Ser africano na cidade: identidade e memória em São Paulo no oitocentos
}

Enidelce Bertin ${ }^{1 *}$

${ }^{1}$ Universidade de São Paulo, São Paulo/SP - Brasil

\section{RESUMO}

Este texto problematiza a posição marginal relegada à contribuição negra na construção histórica de São Paulo através de evidências demográficas e de estudos históricos sobre africanos na cidade durante o século XIX. Discute as transformaçôes na identidade africana dos escravizados e dos negros livres e seus efeitos na apropriaçáo dos espaços da cidade de São Paulo nesse período. $\mathrm{O}$ texto também busca as relaçóes entre as narrativas do desaparecimento do africano e de sua cultura na cidade e a obliteração da memória da presença negra com a construção da ideia de invisibilidade histórica daqueles homens e mulheres.

Palavras-chave: africano; negro; São Paulo; identidade; memória.

\section{To be African in the city: identity and memory in Sáo Paulo during the $19^{\text {th }}$ century}

\section{ABSTRACT}

This text discusses the marginalization of the Black contribution to São Paulo's formation through demographic data and historical studies about Africans living in the city during the $19^{\text {th }}$ century. It discusses changing African identities among both enslaved and free black people and their effects in the appropriation of the urban spaces. The text also discusses relations between narratives about the disappearance of the city's Africans and their culture, the obliteration of the Black presence in collective memory, and the idea of historical invisibility of those men and women.

Keywords: African; afro-descendant; São Paulo; ethnic identity; memory.

DOI: http://dx.doi.org/10.1590/2237-101X02204605

Artigo recebido em 21 de julho de 2019 e aceito para publicação em 18 de maio de 2020.

* Doutora em História pela Universidade de São Paulo, São Paulo / SP, São Paulo/SP - Brasil. E-mail: enidelce@terra.com.br. ORCID: https://orcid.org/0000-0003-1495-8394. 


\section{Ser africano en la ciudad: identidad y memoria en Sáo Paulo en el siglo XIX}

\section{RESUMEN}

Este texto problematiza la posición marginal relegada a la contribución negra en la construcción histórica de São Paulo, a través de evidencias demográficas y de estudios históricos sobre africanos en la ciudad, durante el siglo XIX. Se discute las transformaciones en la identidad africana de los esclavizados y de los negros libres y sus efectos en la apropiación de los espacios de la ciudad de São Paulo durante este período. El texto también busca las relaciones narrativas del desaparecimiento del africano y de su cultura en la ciudad y la anulación de la memoria de la presencia negra con la construcción de la idea de invisibilidad histórica de aquellos hombres y mujeres.

Palabras clave: africano; negro; São Paulo; identidad; memoria.

\section{Apresentação}

Há desvãos, espaços e presenças que são como que resíduos varridos para debaixo do tapete vistoso da paisagem urbana. Sáo seus pontos-cegos, justamente porque revelam seu avesso ou suas vísceras. Eles são o contraponto da identidade pretendida, são a sua mais completa negação, mas por isso mesmo também são a revelação daquilo que ela mais teme revelar: não a máscara exuberante, mas o rosto nu por trás da fantasia (SEVCENKO, 2004, p. 20).

Assim Nicolau Sevcenko apresenta seu ensaio sobre as transformaçóes no urbanismo paulistano e seus efeitos na memória histórica da cidade. Partindo da centralidade perdida da antiga rua São Paulo, no Distrito da Glória, depois Bairro da Liberdade, o autor discute que as mudanças no cenário urbanístico vão muito além da transformação física porque revelam a negligência com a memória de tantas experiências ali vividas. Ficava na rua São Paulo, antes denominada rua dos Ingleses, o Morro da Forca, onde funcionou, desde o século XVIII, o pelourinho. Local de castigos públicos a escravos, aquela rua também sediava o primeiro cemitério público da cidade, o Cemitério dos Aflitos. Criado para ser o cemitério dos anônimos, dos condenados e dos pobres, tornou-se o cemitério dos escravos.

Como, dentre os africanos - fossem eles bantus ou iorubas e jeje-nagôs subsaarianos -, o fulcro da tradição religiosa se concentra no culto dos antepassados, toda a região, o redor da forca e do cemitério, cercou-se da aura da mais elevada sacralidade. A capela do cemitério, chamada de Igreja dos Aflitos, tornou-se um centro devocional da religiosidade popular (SEVCENKO, 2004, p. 19). 
Não obstante a conservação dessa igreja, bem como a preservação da sacralidade do lugar, em meados do oitocentos a forca foi eliminada e o local passou a se chamar Praça da Liberdade, em referência ao Chafariz de mesmo nome, construído defronte ao Curso Jurídico e que homenageava uma revolta popular contra o primeiro Império. Além da modificação do nome do lugar, a desativação do cemitério e o loteamento da região na década de 1880 foram outros passos do processo de urbanização e de ressignificação daquele antigo território negro.

Assim como a regiâo da Glória, outros espaços públicos da cidade, muito caros à memória histórica da escravidão, foram suprimidos ou renomeados como efeito de constantes intervençôes urbanísticas, especialmente a partir do final do século XIX. Além das alteraçôes físicas nos espaços de memória negra, a superposição da narrativa republicana tornou hegemônica a associaçáo do desenvolvimento da cidade com os predicados do trabalho livre e da população eurodescendente.

Este texto procura evidenciar que a população negra foi numericamente significativa na cidade de São Paulo desde pelo menos o final do XVIII, e que, apesar das muitas tentativas de obliteração da memória africana ou afrodescendente, os vestígios das experiências daqueles homens e mulheres continuam sendo recuperados e analisados pelos estudos históricos. Assim, busca-se aqui problematizar a posiçáo marginal relegada à contribuiçáo negra na construçáo histórica de São Paulo. No esforço de enfocar a população negra, lançamos mão de trabalhos historiográficos produzidos com documentação pública variada, com os quais pudemos acompanhar e perscrutar sua presença na cidade do século XIX. Trabalhamos aqui com a hipótese de que, ao longo do tempo, houve um processo de invisibilização do africano e do afrodescendente na história de São Paulo.

\section{Memorialistas, demografia histórica e os africanos em São Paulo}

O empenho para entender a presença negra na cidade de São Paulo deve antes considerar a construção de uma narrativa de seu desaparecimento, a começar pela ideia de ausência de registros documentais. Affonso de Freitas, em 1921, assim explicava o pouco conhecimento sobre as contribuições africanas na cidade:

Quis o acaso que as naçóes Mina, Cassange, Benguela, Moçambique, Congo, dispersas e mal conhecidas entre si, na pátria comum, tivessem sua etnologia legitimamente representada nos álacres ajuntamentos do primitivo arraial do patriarca Tibiriçá, pelas tribos negras que a traficância humana arrojou às plagas paulistas, acaso que os nossos sociólogos da época, lastimavelmente deixaram de aproveitar, nada registrando sobre as modalidades etnológicas com que os forçados colonos se apresentavam em o nosso meio (FREITAS, 1985, p. 153). 
Não se trata apenas de desaparecimento de registro etnográfico como apontou o memorialista do Instituto Histórico e Geográfico de São Paulo (IHGSP). A ideia de uma cidade europeizada foi forjada ao longo do tempo, persistindo como sombra na memória do maior núcleo urbano do país, apesar das evidências da colaboração africana. Nesse sentido, o esforço inicial aqui é para identificar essa população africana e afrodescendente na cidade, observando suas reconstruçôes identitárias como campos da resistência.

No clássico História da cidade de São Paulo (1953), Affonso de E. Taunay refere-se à pequena do planalto nos seguintes termos:

Viveu pacífica e modorrentamente, de 1701 a 1821. Nenhum grande acontecimento veio perturbar-lhe a quietude de uma época de acentuada depressão econômica progressiva, provocada principalmente pelo despovoamento em prol das três grandes regióes do ouro desvendada pelas bandeiras em Minas Gerais, Mato Grosso e Goiás (TAUNAY, 2004, p. 249).

Essa ideia de limitaçóes econômicas e ausência de pujança na cidade também será central na descrição de Ernani da Silva Bruno em História e tradiçóes da cidade de São Paulo (1954). Não é coincidência que ambos tenham publicado seus trabalhos como parte das comemorações do IV Centenário da Fundação da Cidade. Apoiando-se em relatos de viajantes para descrever a cidade, Silva Bruno enfatiza a modéstia do comércio e da estrutura urbana. O autor dá grande destaque ao cenário paulistano do oitocentos para a Faculdade de Direito, cuja movimentação dos estudantes marcava os ritmos da cidade, sendo por isso configurada em burgo de estudantes (BRUNO, 1954).

Taunay refere-se rapidamente à escravidão na cidade, contudo, sem fornecer maiores análises: "Cresceu a importação de africanos como era de esperar numa sociedade, cuja organização se baseava no regime servil. Daí a elevação do coeficiente atribuído à percentagem preta nos censos de princípios do século XIX" (TAUNAY, 2004, p. 260). Se inicialmente o autor apontava a inércia como característica da cidade, em seguida ele indicava que o tráfico havia produzido uma mudança no cenário econômico e demográfico. A caracterização de São Paulo como modorrenta, pobre e desinteressante até o avançar do século XIX foi comum aos autores que descreveram a cidade, entre eles Freitas, Taunay e Silva Bruno.

Entretanto, o historiador Richard Morse, na sua biografia da cidade, apresenta-a com feiçóes um pouco distintas, embora a pesquisa também tenha sido publicada pela Comissão do IV Centenário, em 1954. O autor usou não apenas relatos de viagens e memórias como também séries de documentos históricos produzidos pelos órgãos públicos do oitocentos, incluindo mapas de população. A ampliação no escopo documental permitiu ao autor descrever a participação negra na cidade com maior ênfase:

Significa que as ruas, alamedas e praças da cidade, todas as suas áreas de circulação e reunião pública, estavam de posse de escravos (que constituíam mais de um quarto da população) e 
de homens livres humildes: tropeiros, vendeiros, lavradores. As famílias patriarcais viviam retiradas em seus sobrados (MORSE, 1954, p. 37).

Após a proclamação da Independência, o ritmo de vida na cidade São Paulo será alterado com a instalação de uma tipografia, a fundação da Faculdade de Direito e com um novo formato administrativo centralizado na presidência da província e não mais nas câmaras. A cidade colonial começava a ser enquadrada no sistema nacional de administração, com evidentes impactos políticos e econômicos.

A despeito da importante contribuição dessas obras, especialmente a de Morse, devemos aos estudos em demografia histórica as novas abordagens sobre a cidade e seu evolver econômico e populacional. Para o que nos interessa aqui, ressaltamos o destaque dado à participação africana e afrodescendente no desenvolvimento da cidade ao longo do tempo.

Maria Luiza Marcílio identificou o crescimento econômico da capitania de Sáo Paulo na segunda metade do século XVIII e seus reflexos no espaço urbano da capital como diretamente ligados, primeiramente, à atividade da mineração em Minas Gerais (MARCÍLIO, 2000). Entretanto, com o declínio das extraçóes de ouro nas últimas décadas do século, a agricultura canavieira exportadora e a economia de abastecimento interno garantiram o crescimento demográfico de São Paulo e repercutiram na entrada de mais escravos africanos.

Para analisar o evolver econômico de São Paulo, Maria Luiza Marcílio analisou as estruturas da população desde o final do século XVIII tomando por base as listas nominativas de 1798, 1808, 1818 e 1828, além de listas incompletas de 1765 e do censo de 1836. Nesse estudo, a cidade de São Paulo foi analisada juntamente com as vilas circunvizinhas de Mogi das Cruzes, Santana de Parnaíba, Bragança e Atibaia. Essa observação é relevante na medida em que a delimitação dos arredores da cidade é um dos pontos que afeta a metodologia dos pesquisadores e que resulta em dados distintos entre si.

Mais recentemente, o trabalho de Vidal Luna, Iraci Costa e Herbert Klein expandiu os estudos demográficos com a utilização de mapas não publicados da população e da economia paulistas desde 1750 até 1850 . A cidade de São Paulo aparece representada em 'região da Capital', na qual também estão incluídas Cotia, Guarulhos, Santana do Parnaíba e Juqueri. Os autores enfatizam que a Província de São Paulo importava africanos desde muito antes da fase de exportação do café como mão de obra para a produção de açúcar, aguardente ou mesmo de bens de consumo para o mercado interno regional e nacional (LUNA; COSTA; KLEIN, 2009, p. 193).

A relação entre o impulso econômico e o tráfico escravo é também constatada por Marcondes e Motta, que a sintetizam nos seguintes termos:

Em suma, na virada do século XVIII para o XIX, a capitania de São Paulo apresentava um dinamismo econômico em grande medida assentado na lavoura canavieira e na produção de 
açúcar e demais derivados da cana. De outro lado, a produção e comercialização de animais na capitania e oriundos do Sul movimentavam as estradas, muitas vezes destinadas às Minas e ao Rio de Janeiro, abarcando um conjunto expressivo de pessoas nessa atividade. Esse dinamismo imbricou-se a um significativo crescimento demográfico, para o qual importante contribuição foi dada pelo aumento da população escrava proveniente da África (MARCONDES; MOTTA, 2017, p. 27-56).

O estudo com inventários realizado por Maria Lucília Viveiros Araújo demonstra que essa vitalidade da província no início do oitocentos atingia o enriquecimento dos negociantes da capital, especialmente daqueles que investiram em propriedades, dívidas ativas e em escravos.

O plantel de escravos domésticos dos moradores da cidade continuou crescendo na primeira metade do oitocentos, especialmente para os proprietários com negócios urbanos e rurais, ou seja, todos os índices indicam que a riqueza dos moradores da capital crescia ao mesmo tempo que se desenvolviam as novas fronteiras agrícolas (ARAÚJO, 2006, p. 149).

São Paulo está localizada entre o interior e o litoral, entre as zonas agrícolas e a região de embarque para exportação. Essa posição geográfica intermediária favoreceu o estabelecimento na capital de negociantes e, por sua vez, de escravos. Assim, o tráfico aberto e a economia centrada no trabalho escravo incidiram no aumento da participação africana na província e também na sua capital.

Essas são algumas das pesquisas que apontam para uma outra direção interpretativa de São Paulo em relação àquela realizada por Taunay e Silva Bruno. Contudo, não é o objetivo deste trabalho a análise do evolver econômico da cidade, tampouco a discussão das narrativas que refutaram ou não a ideia da irrelevância econômica até a fase áurea do café. ${ }^{1}$

Pretendemos aqui seguir as trilhas de Maria Odila Leite da Silva Dias, Maria Cristina Wissenbach e Regiane Mattos, historiadoras que investigaram a presença africana na cidade de São Paulo do século XIX (DIAS, 1995; WISSENBACH, 1998; MATTOS, 2006). Ao fazer esse caminho, buscamos trazer à luz uma importante fatia da população paulistana, que a despeito de sempre estar representada nos censos populacionais, ainda carece de lugar na memória desta cidade.

Para avaliar os números da população de africanos em São Paulo, podemos lançar mão dos recenseamentos demográficos. O primeiro censo da província foi realizado em 1836, sob a coordenação de Daniel Pedro Müller. Até 1872, quando foi realizado o primeiro censo geral do Brasil, as tentativas de escrutínio demográfico deram-se regionalmente e com resultados nem sempre livres de erros ou inconsistências. Como alternativa à falta de

\footnotetext{
${ }^{1}$ Para uma discussão sobre as interpretaçóes dos memorialistas, ver Medicci (2005).
} 
recenseamentos amplos, os pesquisadores têm utilizado as listas nominativas de habitantes, assim como os registros paroquiais de batismo e óbito, cujas séries documentais permitem igualmente análises demográficas.

Importante considerar que nos dados populacionais da cidade de São Paulo, em geral estão também computados moradores dos arredores, como já foi apontado acima; ora a cidade está associada às áreas rurais do seu entorno como Guarulhos, Mogi das Cruzes, Atibaia e Cotia, ora está indicada juntamente com Santo Amaro e Juqueri. Isso dificulta a simples comparaçáo dos números de um ano a outro. Uma tentativa de acompanhar esses dados ao longo do tempo pode ser verificada no quadro abaixo, amparado em levantamentos de Maria Luiza Marcílio, Regiane Mattos, no censo de Müller, e no primeiro censo geral de 1872.

Quadro I - População da cidade de São Paulo no século XIX

\begin{tabular}{|c|r|r|r|r|r|}
\hline Ano & \multicolumn{1}{|c|}{$\mathbf{1 8 3}^{(\mathbf{1})}$} & \multicolumn{1}{|c|}{$\mathbf{1 8 1 4}^{(\mathbf{2})}$} & \multicolumn{1}{c|}{$\mathbf{1 8 2 4}^{\left({ }^{(3)}\right.}$} & \multicolumn{1}{c|}{$\mathbf{1 8 3 6}^{(\mathbf{4})}$} & \multicolumn{1}{c|}{$\mathbf{1 8 7 2}^{(\mathbf{5})}$} \\
\hline População geral & 24.311 & 23.054 & 25.321 & 21.979 & 31.365 \\
\hline Livres & 17.985 & 17.236 & 19.544 & 16.614 & 27.537 \\
\hline Escravos & 6.326 & 5.818 & 5.777 & 5.319 & 3.818 \\
\hline \% Escravos & $26 \%$ & $25 \%$ & $23 \%$ & $24 \%$ & $12 \%$ \\
\hline Africanos & 1.178 & 727 & 778 & 1.984 & 463 \\
\hline \% Escravos africanos & $19 \%$ & $12 \%$ & $13 \%$ & $37 \%$ & $12 \%$ \\
\hline
\end{tabular}

Fontes: Marcílio (2000); Mattos (2006); Müller (1836); Censo de 1872.

(1) Marcílio (2000). A autora utiliza as listas nominativas de habitantes.

(2) Mattos (2006). A autora utiliza registros de batismos e óbitos e os maços de população das Companhias de Ordenanças (na região central) e freguesias de Santana, Freguesia do Ó e Penhas, excluindo, portanto, as vilas vizinhas.

(3) Mattos (2006). Nesta coluna estáo sendo considerados os dados de 1825.

(4) Bazzanezi (1998). Nesse trabalho, o censo de Daniel P. Müller é conferido e corrigido em alguns dados. Müller trabalha com três freguesias centrais: Sé, Brás e Santa Efigênia e seis periféricos: Conceição, Nossa Senhora do Ó, Cotia, Nossa Senhora da Penha, São Bernardo e Juqueri.

Até a década de 1830, por volta de um quarto da população da cidade de São Paulo era escrava. Nessa década, o percentual de africanos entre os escravos subiu a 37\% como reflexo da intensificação do tráfico atlântico e da demanda agrícola na província. Luna e Klein mostram que quando a população africana é observada também no entorno rural da cidade, o índice chega a 49\% de presença africana entre os escravos em 1829, e 57\% quando é considerada a província como um todo (LUNA; KLEIN, 2005). O fim do tráfico e as condiçóes da escravidáo explicam a diminuição de africanos entre os escravos na década de 1870, bem como a própria queda do número geral de escravos. Sem a entrada de africanos novos e com um sistema de trabalho violento e predatório, a população escrava diminuiu no país inteiro. 
Entretanto, o pequeno percentual de escravos na cidade nas últimas décadas do século não significou o desaparecimento da população negra livre ou liberta.

\section{Distribuição étnica dos africanos pela cidade}

A partir dessa noção geral da proporção de africanos em São Paulo, podemos tentar perscrutar a distribuição étnica deles. Para tanto, o trabalho de Regiane Mattos é esclarecedor. Servindo-se de 1.386 registros de batismo e a classificação usada por Mary Karash, a autora constatou que os grupos de procedência africanos presentes na cidade estavam assim distribuídos: a maioria foi identificada como procedente da Guiné (44\%), que era uma forma genérica de referir-se à África; também genericamente são indicados como procedentes da África (17\%) e da Costa (12\%) (MATTOS, 2006, p. 103). Houve ainda a identificação de $5 \%$ da Costa da África e $2 \%$ da Costa da Guiné. Na documentaçâo analisada, Mattos encontra $11 \%$ de escravos da região Centro Ocidental africana (com menção aos seguintes termos: angola, cabinda, cassange, congo, monjolo, rebolo, mossangona, benguela, Costa de Cabinda e gabão); da região Ocidental eram 6\% dos batismos (que aparecem identificados com as expressóes mina, nação mina, Costa da Mina, nação calabar e minaguçá). Referências a Moçambique ou Costa de Moçambique apareceram em apenas $1,5 \%$ dos batismos.

Do mesmo modo, Mattos analisou 1.691 registros de óbitos, o que rendeu a seguinte distribuição segundo a região africana de procedência: Guiné (47\%), África (19\%), da Costa (17\%), Centro Ocidental (6\%), Costa da África (3\%), Costa da Guiné (2\%), Ocidental (2\%) e Oriental (menos de 1\%). A regiáo Centro-Ocidental aparece identificada nos registros de óbitos com as expressões angola, cabinda, cassange, congo, munjolo, rebolo, benguela, cabundá, ganguela e moanje.

As cartas de alforria registradas na cidade de São Paulo durante o século XIX não foram generosas na informação sobre os grupos étnicos ou de origem dos escravos. De um total de 1.338 escravos alforriados, $58 \%$ não tiveram informada sua origem, nem mesmo genericamente; dentre aqueles com essa informação, 28\% eram nascidos no Brasil e 12\%, na África (BERTIN, 2004, p. 111). Nessa documentação, parece que não havia preocupação do proprietário ou do cartório em especificar a procedência ou os grupos étnicos dos alforriados, de modo que entre os nascidos no Brasil, 95\% receberam a classificação de "crioulo". Dentre os poucos africanos identificados nos registros de alforria, quase a metade foi genericamente chamada "de nação". Apenas uma pequena parcela trazia junto ao nome uma associação com região geográfica africana ou grupo étnico. Mina, guiné, costa, costa da guiné, costa da mina, nagô, congo, benguela, cabinda, angola, cassange, monjolo, rebolo e moçambique foram as expressóes usadas pelos cartórios nos registros das cartas de liberdade de indivíduos africanos. 
Além dos escravos e libertos, a população de africanos na cidade era composta pelos chamados africanos livres. Eram assim chamados aqueles que, trazidos da África para serem escravizados, foram liberados com base na lei de 1831 e mantidos sob a guarda do governo provincial. Este usava os serviços dos serventes ou os entregava a arrematantes interessados em fazer o mesmo. Os africanos livres que prestaram serviços na cidade de São Paulo ou nas obras públicas da província, em sua maioria haviam desembarcado no Rio de Janeiro (MAMIGONIAN, 2017). As características desse grupo de africanos no planalto paulista guardam, portanto, semelhanças com a demografia do tráfico naquele porto.

Um exercício de observação sobre os grupos de procedência dos africanos livres que foram trazidos a Sáo Paulo pode ser feito a partir de duas listas nominais de 1851; uma listando os serventes da Fábrica de Ferro São João do Ipanema, localizada na regiáo de Sorocaba, e outra discriminando os enviados da Casa de Correçáo do Rio de Janeiro para as obras públicas na Província de São Paulo.

Na primeira, organizada pela direção da Fábrica de Ferro, podemos observar a indicação dos seguintes grupos procedentes da África Centro-Ocidental: angola, barundo, benguela, bié, cabinda, cacondo, cocundo, cassange, congo, corualle, cogungui, lualle, lumbe, moambe, monjolo, rebolo, ugarangue, umbuira; da África Ocidental, o grupo mina; da África Oriental, macua, moçambique, mogange, mucina, quilimane. Além desses, outros grupos foram citados, sem que tenhamos identificado a região da África correspondente: caburuos, caçambo, chipeta, cobia, cocanete, colualle, columba, colunda, coluntembuo, cosongá, coturumba, cranho, cucua, ganga, garangue, nequipongo, noumbo, ozamba, piocas, quimatrangle, quitingui, suma, utepigo, utinanda. ${ }^{2}$

Na segunda lista, as obras públicas na província de São Paulo recebiam africanos dos seguintes grupos de procedência: da África Centro-Ocidental, angola, bambi, benguela, bomba, cabinda, cabunda, cassange, congo, ganguela, maombe, moange, monjolo, muteca, muxicongo, rebolo, ubaca; da África Ocidental, calabar; da África Oriental, macua, moçambique, mussena, quilimane. Os grupos cuja regiấo africana não foi identificada são chuatama, mupungo, mussume, quebombo. ${ }^{3}$

As listas de africanos livres costumavam trazer os registros de procedência tal como informados pelo tráfico, até que, com o tempo de Brasil, a identificação da "nação" africana se tornasse mais genérica. Isso pode explicar a variedade de termos para os grupos étnicos ou de procedência dos africanos livres recém-chegados, diferentemente do que foi observada nas cartas de alforrias ou nos registros paroquiais, como visto acima.

\footnotetext{
${ }^{2}$ Arquivo Público do Estado de São Paulo - APESP, CO 5216. Relação nominal dos africanos livres da Fábrica de Ferro São João de Ipanema, 1851.

${ }^{3}$ APESP, CO 5451 - Relação nominal dos africanos livres remetidos da Casa de Correção para a Província de São Paulo, 1851.
} 
Uma terceira lista aqui usada refere-se aos africanos livres que receberam carta de emancipação em 1864 depois de décadas de serviços públicos. Nesta, também podemos observar significativa mudança nas identificaçóes fornecidas.

Centrando esforços em entender a presença africana na cidade de São Paulo, essas informaçōes sobre os grupos étnicos ou de procedência dos escravos e africanos livres são indícios importantes a serem considerados uma vez que podem indicar formas de organizaçáo na cidade, bem como a construção de novas identidades étnicas.

Quando observados os mesmos africanos livres em tempos diferentes, notamos assimilação de novas identidades. Um exemplo é a comparação dos africanos que chegaram a São Paulo em 1851 e os mesmos homens em 1864, quando obtiveram a emancipação:

Quadro 2: Comparação de grupos étnicos nas listas de africanos livres: ${ }^{4}$

\begin{tabular}{|c|c|c|}
\hline Africano livre & Nas listas de 1851 & Na emancipaçáo em 1864 \\
\hline Amaro & Ubaca & Congo \\
\hline Aniceto & Quebombo & Cabinda \\
\hline Baltazar & Mussena & Moçambique \\
\hline Bonifácio & Cacondo & Benguela \\
\hline Caio & Cabinda & Moange \\
\hline Cosme & Moange & Monjolo \\
\hline Emília & Benguela & Cabinda \\
\hline Gaspar & Monjolo & Angola \\
\hline Manuela & Muteca & Cabinda \\
\hline Olegário & Macua & Benguela \\
\hline Paulo & Angola & Congo \\
\hline Zeferino & Quilimane & Moçambique \\
\hline
\end{tabular}

Fontes: APESP - CO 5216 - Relação nominal dos africanos livres da Fábrica de Ferro São João do Ipanema, 1851; APESP - CO 5451. Relação nominal dos africanos livres remetidos da Casa de Correção para a Província de São Paulo; APESP - EO 1487. Matrícula de africanos emancipados, 1864.

A preservação da região africana correspondente nas novas identificaçóes sugere uma apropriação e ressignificação étnicas pelo africano ao longo do tempo. Amaro, que era ubaca, tornou-se congo. Qual é o significado dessa mudança? Uma resposta pode ser a de que ele, ao identificar-se como congo, inseria-se em um grupo maior de africanos. Contudo, vale perguntar se essa mudança foi uma escolha de Amaro e, náo tendo sido, como e por que ele a assumiu.

\footnotetext{
${ }^{4}$ Publiquei uma versão dessas listas em "Construindo novas identidades - a emancipação dos africanos livres" (4 Encontro Escravidão e Liberdade no Brasil Meridional, Curitiba, 2009) e em Os meias-caras. Africanos livres em São Paulo no séc. XIX (Editora Schoba, 2014).
} 


\section{Recriando identidades étnicas}

O quadro acima suscita outras questões: a identidade étnica trazida da África persevera por quanto tempo aqui no Brasil? Em que medida o tráfico e a escravização afetaram tais identidades? Entre o africano e o afrodescendente havia fronteiras culturais e étnicas?

Flávio Gomes, Juliana Farias e Carlos Soares aplicaram o conceito de recriação ou reinvenção de identidades étnicas na análise dos grupos étnicos dos escravos no Rio de Janeiro. Para os autores, os africanos produziam, nas ruas daquela cidade, novas naçóes e misturas identitárias, étnicas e culturais.

Era em contextos diversos que os africanos inventavam-se em termos de 'naçóes' e outros arranjos, articulando-se numa extraordinária cidade atlântica. Corpos, línguas e mentes eram remarcados permanentemente em termos sociais e étnicos. Africanos - e também os crioulos - não tinham uma única identidade, mas várias. Símbolos, marcas, penteados e outros sinais ganhavam, mantinham, mudavam ou perdiam significados (FARIAS; SOARES; GOMES, 2005, p. 48).

Tomando emprestado esse conceito de recriação de identidades, podemos perguntar como se organizavam os africanos na cidade de São Paulo e quais são os aspectos culturais resultantes dessa organização. Considerando que as culturas africanas não são estáticas ou cristalizadas, mas são experiências de criação e de recriação transétnica, vale aqui fazer uma tentativa de investigação sobre esse processo de recriação e sua relação com os espaços da cidade de Sáo Paulo do oitocentos.

Se consideramos que a recriação da identidade étnica se dá no convívio e na apropriação da cidade, uma possibilidade de observação está nas formas de sociabilidade daqueles africanos. As irmandades religiosas como espaço de encontro e de trocas culturais foram de enorme importância para a construção dessa identidade em diferentes localidades brasileiras. ${ }^{5}$ No caso de São Paulo no século XIX, os grupos étnicos africanos não foram definidores de posição hierárquica no interior das irmandades. Apenas no caso da irmandade de Nossa Senhora dos Homens Pretos, organizada pelos escravos angola, havia a prerrogativa desse grupo para o cargo de rei e de rainha; já os demais cargos dessa irmandade eram acessíveis a todos os homens pretos (MATTOS, 2006). Sem uma restrição a determinado grupo étnico, as igrejas de Nossa Senhora do Rosário, de Santa Ifigênia e de São Benedito, que eram, respectivamente, as sedes das irmandades dos Homens Pretos, de Santo Elesbáo e Santa Ifigênia, e de São Benedito, aglutinavam, seja no seu interior, seja nos arredores, homens e mulheres africanos ou crioulos, escravos, livres ou libertos. As irmandades configuravam-se não apenas pontos de encontro físicos na cidade, mas locais transétnicos onde as identidades

\footnotetext{
${ }^{5}$ Para o caso de Minas Gerais, ver Scarano (1978).
} 
culturais eram preservadas e recriadas. Antonio Egydio Martins assim descreve o intenso festejo negro na igreja de N.S. do Rosário:

[...] Realizavam-se também, em frente à mesma igreja, festejos populares, postando-se ali um numeroso bando de pretos africanos, que executavam com capricho a célebre música denominada Tambaque (espécie de Zé Pereira), cantando e dançando com as suas parceiras, que, adornadas de rodilha de pano branco na cabeça, pulseira de prata e rosário de contas vermelhas e ouro ao pescoço, pegavam no vestido e faziam requebrados, sendo por isso vitoriados com uma salva de palmas pela numerosa assistência [...] (MARTINS, 2003, p. 324).

Além das igrejas, as ruas da cidade de São Paulo conformaram lugares de intensa sociabilidade entre os trabalhadores livres, libertos ou escravos que nelas circulavam. As bicas ou chafarizes, importantes locais de abastecimento de água, eram, também, lugares de encontros, conversas, brincadeiras, e, não raro, de brigas. Do mesmo modo, as pontes sobre os rios Anhangabaú e Tamanduateí reuniam escravos e libertos, africanos ou crioulos no trabalho e no lazer (WISSENBACH, 1998, p. 179-180).

Diversos outros cantos do espaço urbano foram apropriados e ressignificados por africanos e crioulos no século XIX: a região do Caaguaçu e Alto do Lavapés para moradia; o entorno das igrejas e a rua das Casinhas para trabalho e diversão; a região do Campo Redondo, próximo ao Jardim Público, para festas e religiosidade; a regiáo da Glória e o cemitério dos Aflitos. O uso compartilhado desses locais reforça menos as especificidades do grupo de procedência africana e muito mais uma identidade construída no contexto da escravidão, como ficou indicado no quadro acima. Tornaram-se territórios afrodiaspóricos (SANTOS, 2018).

Náo obstante a presença contínua e intensa de africanos nesses espaços da cidade, estes não foram adequadamente preservados como lugares da memória negra em São Paulo, contribuindo para uma equivocada noção de invisibilidade e até de inexistência desses sujeitos.

O curioso caso a seguir pode trazer luzes para a questão das identidades entre os africanos. Embora não tenha ocorrido na cidade de São Paulo, guarda relação com o que foi apontado acima. Em 1864 um grupo de africanos livres lotado nos trabalhos em Itapura, localidade entre Sáo Paulo e o atual estado do Mato Grosso do Sul, recebeu carta de emancipação. A lista de todos os emancipados trazia nomes compostos como Agostinho Piracicaba, como se vê no quadro 3. Em 1851, esses serventes chegaram a Itapura levados da Fábrica de Ferro São João do Ipanema, motivo pelo qual foram discriminados em lista. Cotejando as listagens de 1851 e a de 1864, pudemos notar uma importante alteração: ao longo dos anos o grupo de procedência africano foi substituído por um cognome relativo a uma localidade brasileira e muitas vezes com referência indígena. ${ }^{6}$

\footnotetext{
${ }^{6}$ Esse caso foi apresentado no $4^{\circ}$ Encontro Escravidão e Liberdade no Brasil Meridional (Curitiba, 2009) e descrito em Os meias-caras... (2014, p. 116).
} 
Quadro 3 - Listas de Africanos Livres em 1851 e em 1864:

\begin{tabular}{|c|c|}
\hline $\begin{array}{c}\text { Nome com grupo de procedência } \\
(\mathbf{1 8 5 1 )}\end{array}$ & Nome alterado (1864) \\
\hline Agostinho Benguela & Agostinho Piracicaba \\
\hline Alberto Garangue & Alberto Urububungá \\
\hline Aleixo Macua & Aleixo de Limeira \\
\hline André Couvalle & André Pirataca \\
\hline Antenor Barundo & Antenor Bauru \\
\hline Apolinário Nequipongo & Apolinário Alambari \\
\hline Benedito Mucena & Benedito Coruçá \\
\hline Bento Barundo & Bento Iguatemy \\
\hline Bernardino Rebolo & Bernardino Corumbataí \\
\hline Brígida Cassange & Brígida Bertioga \\
\hline Canuto Cobia & Canuto de Igassú \\
\hline Casemiro Colunda & Casemiro Cabreúva \\
\hline Claudiano Cocundo & Claudiano Poconé \\
\hline Cosme Cocanete & Cosme Banharão \\
\hline Crispim Colunda & Crispim Jataí \\
\hline Crispiniano Bié & Crispiniano Vacaria \\
\hline Damásio Marambe & Damásio Guaratinguetá \\
\hline Daniel Benguela & Daniel Lavradio \\
\hline Deoclesiano Cosongá & Deoclesiano Araçangá \\
\hline Domingas Angola & Domingas Ivaí \\
\hline Engracia Rebolo & Engracia Serra \\
\hline Felisberta Monjolo & Felisberta Cerqueira \\
\hline Florencio Quilimane & Florêncio Corumbá \\
\hline Fulgêncio Quilimane & Fulgêncio Avanhandava \\
\hline Gregório Quilimane & Gregório Macaúba \\
\hline Honorata Benguela & Honorata Pirataca \\
\hline Jacinta Benguela & Jacinta Corumbá \\
\hline Joaquina Benguela & Joaquina Iguatemy \\
\hline Julião Quitingui & Julião Quitingui \\
\hline Luciana Angola & Luciana Gameleira \\
\hline Maria Bernarda Benguela & Maria Bernarda Corumbataí \\
\hline Paulo Angola & Paulo Guarany \\
\hline Pelaio Moçambique & Pelaio Ivaí \\
\hline Silvério Mogange & Silvério Queluz \\
\hline Teodora Moange & Teodora Urubupungá \\
\hline Venceslau Congo & Venceslau Xavantes \\
\hline
\end{tabular}

Fontes: APESP - CO 5216 folder 4. Relação nominal dos africanos livres da Fábrica de Ferro São João do Ipanema, 1851; APESP - EO 1487. Matrícula de Africanos Emancipados - 1864. 
Notamos que em outros estabelecimentos, ao longo do tempo, também houve alteraçóes nas identificaçôes dos grupos étnicos dos africanos livres, porém, sempre ficou mantida a relação da nova identificação com a região africana de procedência. Apenas nessa lista de Itapura constatamos essa curiosa e radical mudança, o que era um indício de que estava naquela colônia militar o responsável pelas renomeaçôes.

$\mathrm{Na}$ investigação dos motivos desse ato insólito, descartamos a possibilidade de ter sido promovido pelos próprios emancipados, dado o tema escolhido e a unanimidade na adesão. Significativo, também, é que isso se deu no processo de emancipação dos africanos livres. Localizamos um ofício de 1862, entre a diretoria da colônia e a presidência da província, no qual o diretor de Itapura se queixava de que as listas nominais dos serventes recebidos náo faziam clara distinçáo entre africanos livres e escravos. Ao cotejar a lista de $1851 \mathrm{com}$ a relação dos emancipados em 1864 podemos constatar que a alteração do segundo nome dos africanos permitiu essa diferenciação, ao mesmo tempo em que fez desaparecer a referência à origem africana daqueles homens. É muito significativo que os novos sobrenomes conferidos àqueles africanos parecem querer produzir uma vinculação com o Brasil e com a condição de emancipação.

As alteraçóes nos grupos de procedência promovidas pelos diferentes agentes do tráfico, proprietários e administradores públicos, resultaram no esmaecimento das especificidades de grupos africanos ao longo do tempo de permanência no Brasil até desaparecerem por completo, como no caso de Itapura. A ideia de que os africanos livres eram estimulados a não se identificarem como africanos - daí que os termos vão ficando mais genéricos - fica evidente nesse caso.

Um outro caso, desta vez recuperado por Regiane Mattos, sugere a recriaçáo de identidade para além da origem africana. Em 1831, o proprietário da chácara Bonsucesso, localizada nos arredores da cidade de Sáo Paulo, foi surpreendido pelo desafio de uma malta com mais de cinquenta capoeiras em frente ao seu portâo dizendo que "queriam mostrar aos negros cariocas a primponeza dos negros paulistas". No seu depoimento, o proprietário comentou: "É me desconhecido o motivo dessa rivalidade, mas os meus ladinos me informam que náo é outro mais que o de uns serem do Rio de Janeiro e outros de São Paulo ao mesmo tempo que todos eles são africanos". ${ }^{7}$

A identificação com a cidade é explícita, afinal é isso que justifica o desafio dos capoeiras. Mais do que a condição de serem todos escravos africanos, há aqui a valorização de uma nova identidade recriada no Brasil e que, aparentemente, estava desvinculada do grupo de procedência. Tomando o conceito de identidade defendido por Soares, Gomes e Farias, de que as diferenças étnicas são diluídas para que semelhanças fossem construídas, podemos entender que, para aqueles escravos, reconhecer-se como paulistas resultava em pertencimen-

\footnotetext{
${ }^{7}$ APESP - CO 867, d. 98, 05/03/1831. Ofício de Antonio Joaquim de Macedo ao juiz de paz (apud MATTOS, 2006, p. 11).
} 
to a um lugar e a um grupo (SOARES; GOMES; FARIAS, 2005). O estranhamento do proprietário se deu porque ele entendia que a origem africana seria suficiente para unificar o grupo. O que ele não percebeu é que as identidades africanas que ele reconhecia também haviam sido inventadas - e não necessariamente pelos próprios africanos.

Em seu estudo clássico sobre o cotidiano da cidade de São Paulo, Maria Odila da Silva Dias analisa a preponderância feminina no comércio pelas ruas como um traço marcante da cultura africana. Contudo, a experiência do tráfico e da escravidão impóe grande impacto, de modo que acabam por transformar aquela cultura. "A escrava africana em São Paulo não vivia, no dia-a-dia, papéis prescritos e herdados pelos costumes de linhagem, antes um processo brutal de aculturação, o aprendizado de novos ofícios e a improvisação de todos os laços sociais primários e de comunidade" (DIAS, 1995, p. 158-159). No processo de assimilação, uma nova identidade foi construída e, nesta, nem sempre a vinculação com a África foi o elemento fundamental.

Na São Paulo da segunda metade do século XIX, com poucos africanos em meio aos escravos e negros livres, houve uma aproximação entre os diferentes grupos étnicos nos postos de trabalho, na circulação diária, nos espaços de convivência. Essa diluição das identidades africanas guarda relação com um processo de apagamento da memória da escravidão na cidade e de construção da invisibilidade daqueles sujeitos.

Discutindo as tradiçóes na cidade de São Paulo de fins do oitocentos, Affonso de Freitas assim apresenta a sobrevivência das festas populares:

Unicamente as 'congadas', 'batuques', sambas, os 'moçambiques', ainda se realizavam pelas ruas, de ordinário no largo de S. Bento ou junto às igrejas de S. Benedito [...], e do Rosário, após o recolhimento das procissóes: reprimidas por anacrônicas, foram substituídas pela dança dos 'caiapós', arremedo dos costumes daqueles selvícolas, sem valor étnico, organização artificiosa que era, de pretos crioulos da Capital (FREITAS, 1985, p. 150).

Para o memorialista, os crioulos teriam assimilado aspectos da cultura indígena, a ponto de substituírem as danças africanas por outras da terra. Saudosista e um tanto adverso ao ecletismo cultural que despontava na cidade, o autor lastima o esquecimento das práticas culturais tradicionais paulistas, inclusive as africanas:

O negrume formava então tantos grupos quantas as origens étnicas em que se subdividia, e as danças e os cantares rompiam ao ruído seco do reque-reque, ao som rouco e soturno dos tambus, das puítas e dos urucungos que, com a marimba solitária, formavam a coleção dos instrumentos africanos conhecidos em nossa terra. [...] Com a morte do último africano em São Paulo, desapareceram as tradiçôes, em sua pureza, da raça negra e hoje o samba, amálgama das múltiplas danças regionais, da capoeira, do lundu, do jongo, hatucado em quase todas as 
fazendas e sítios do Estado de São Paulo e fundamente desfigurado pelo perpassar do tempo e da civilização, é tudo quanto resta dos costumes característicos do povo oprimido (FREITAS, 1985, p. 152-153).

Para Freitas, na década de 1920 já não havia africanos na cidade; a cultura africana autêntica, pura, se perdera. Ele não cogita as trocas e misturas culturais ou os substratos africanos ainda presentes nas tradições da cidade. Conceitos como o de recriação cultural não faziam parte do escopo analítico do historiador do Instituto Histórico e Geográfico de São Paulo.

Apenas nos anos de 1960 essa teorização difundida pelo antropólogo F. Barth permitiu compreender os aspectos culturais de um determinado grupo como produtos da forma como ele se organiza socialmente (BARTH, 1976). Para este autor, é a autodefinição de indivíduos como componentes de um determinado grupo o que o configura. Além disso, ele defende que não há uma fronteira clara entre os grupos étnicos, já que estão em constante redefinição.

Sabemos que no caso dos africanos, o tráfico e a escravização contribuíram sobremaneira para a formação e redefinição da sua identidade étnica. Portanto, diversamente de buscar a essência africana em São Paulo - e não encontrá-la, porque ela não existe - é mais interessante e eficaz promover estudos que investiguem o que dava significado à identidade negra na cidade.

\section{A construção da invisibilidade}

A narrativa reproduzida em Freitas do desaparecimento do africano e da sua cultura em São Paulo é muito significativa porque seus ecos serão ouvidos ao longo de todo o século XX. À imagem de uma cidade caipira, com grande influência da cultura indígena e também negra, haverá a sobreposição de um quadro com elementos europeus, brancos e, por conseguinte, modernos. Nessa representação de cidade concebida inicialmente no interior do IHGSP, o lugar das heranças africanas ou caboclas é o do pitoresco e não o da cultura e da história; é um lugar idílico porque havia a crença na pureza essencial da cultura.

Ao longo do tempo, a memória da presença negra na cidade de São Paulo sofreu diversas tentativas de empalidecimento. Isso pode ser percebido na modernização dos traçados das ruas e no consequente desaparecimento de vias e construçóes, na alteração dos nomes de logradouros e de espaços caros à presença negra, assim como no esquecimento de homens e mulheres que foram significativos para a história e cultura negra na cidade. Um exemplo desse processo se deu em 1872 quando a Câmara decidiu pela destruição de moradias de negros e do cemitério anexo à Igreja do Rosário, pertencente à Irmandade de Nossa Senhora do Rosário dos Homens Pretos, para a construção do Largo do Rosário, que mais tarde seria renomeado Praça Antonio Prado (MARTINS, 2003, p. 325). A eliminação daquele espaço 
de grande significado simbólico para os africanos e a posterior renomeação do lugar são indicativos de qual memória a cidade quis preservar, já que homenageia o ilustre prefeito da cidade, homônimo do avô comerciante de escravos.

Ao mesmo tempo em que a administração pública criava mecanismos para afastar a presença negra dos espaços mais valorizados da cidade, algo similar se dava no campo da memória histórica. Durante a gestão de Afonso d'Escragnolle Taunay no atual Museu Paulista (1917 a 1945), a memória nacional passou a ser construída relativamente a São Paulo. Nessa construçáo, iniciada no IHGSP e propagada na conformação do museu, São Paulo estaria dotada do protagonismo desde a colônia, quando as Bandeiras permitiram o desbravamento dos sertóes. Um resultado desse processo é que a imagem do paulistano como herdeiro dos bandeirantes e, por isso, uma "raça de gigantes", foi escolhida para fundar a elite de São Paulo (BREFE, 2000, p. 239-259). Raquel Rolnik é categórica a respeito do lugar reservado à população negra no final do século XIX:

$\mathrm{Na}$ cidade que se quer civilizada, europeizada, o quilombo é uma presença africana que não pode ser tolerada. Isso se manifesta desde a formulação de um código de posturas municipal em 1886, visando proibir essas práticas presentes nos territórios negros da cidade: as quituteiras devem sair porque 'atrapalham o trânsito'; os mercados devem ser transferidos porque 'afrontam a cultura e conspurcam a cidade'; os pais-de-santo não podem mais trabalhar porque são 'embusteiros que fingem inspiração por algum ente sobrenatural' (ROLNIK, 1989, p. 33).

A consequência imediata das políticas de afastamento das práticas culturais negras das regiôes mais valorizadas da cidade será a formação de territórios negros nos bairros periféricos. Entretanto, esse "racismo à paulista" estabelecia uma segregação informal, pautada pela discriminação racial e socioeconômica, embora sem configurar como guetos os cantos de ocupação negra e pobre nas bordas da cidade (DOMINGUES, 2004).

Se, no início do século XX, o Lavapés e a Barra Funda eram os bairros mais negros de São Paulo, ao longo das décadas a população afrodescendente foi se dispersando por toda a periferia da cidade, mas com maior concentração na região noroeste. "Assim, de Casa Verde (com 22,14\%) se passa por Limão (com 26,14\%), Nossa Senhora do Ó (com 26,67\%), Pirituba (com 26,6\%) e Vila Nova Cachoeirinha (com 27\%) para chegar a Brasilândia - também conhecida como 'África paulistana' -, com 49\% de pretos e pardos" (ROLNIK, 1989, p. 38).

O Censo Demográfico de 2010 contabilizou 11,2 milhôes de habitantes na cidade de Sáo Paulo, sendo cerca de 4,1 milhóes (37\%) declarados negros (pretos ou pardos). ${ }^{8}$ O Censo também confirma que cada vez mais a população negra foi se distanciando do

\footnotetext{
${ }^{8}$ IBGE. Censo 2010. Disponível em http://produtos.seade.gov.br/produtos/retratosdesp/view/index.php?tem aId $=1$ \&indId $=5 \&$ locId $=3550308 \&$ busca $=$
} 
centro da cidade. Se na década de 1980 a região noroeste tinha a maior população negra, agora a maior concentração de afrodescendentes na cidade de São Paulo está nos bairros dos extremos das zonas sul e leste: Parelheiros com $57,1 \%$ de negros na população, seguidos por M'Boi Mirim (56\%), Cidade Tiradentes (55,4\%) e Guaianases (54,6\%), os dois últimos na zona leste. ${ }^{9}$

Portanto, a posição secundária e marginal a que foram relegados os negros na história da cidade de São Paulo vem de longa data. A condiçấo de sujeito histórico dos africanos e descendentes foi minorada ou ignorada já na narrativa da abolição e depois na construção de uma memória do desenvolvimento da cidade que, somada aos ideais racialistas, resultou em apagamento de suas contribuiçôes históricas, demográficas e culturais para São Paulo e para o país. Desse modo, a negação de uma memória da participação dos afrodescendentes na construção da cidade facultou a permanência de uma narrativa para Sáo Paulo como metrópole moderna porque branca e europeizada. Esse discurso sobrevive apesar das estatísticas demográficas. Entretanto, a depender das novas geraçóes de historiadores e seus estudos, novas facetas da reordenação identitária da população negra poderão ser melhor conhecidas (SANTOS; AZEVEDO, 2018).

$\mathrm{Na}$ contramão do ainda persistente enunciado de São Paulo como uma cidade com feiçôes europeias, a fisionomia da região central da cidade tem adquirido novas matizes com a presença marcante de refugiados e imigrantes angolanos, senegaleses, nigerianos e congoleses, além dos haitianos, bolivianos e peruanos. ${ }^{10}$ As cores vibrantes de suas vestes e o som estrangeiro de suas falas evidenciam sua presença como forasteiros. Resta saber se eles serão percebidos ou se continuarão invisíveis aos olhos da cidade, como aconteceu com a população africana de séculos passados e como ainda acontece com os negros paulistanos na atualidade.

\footnotetext{
${ }^{9}$ Centro de Estudos das Relaçóes de Trabalho e Desigualdades - CEERT. Disponível em: http://www.ceert. org.br/noticias/dados-estatisticas/9503/levantamento-mostra-distribuicao-da-populacao-negra-em-sao-paulo. Acesso em: 21 jan. 2019. Em relação à Sé, a distância dos bairros é a seguinte: na região Noroeste: Casa Verde, 7 Km; Brasilândia, 16 Km; na região Sul: Parelheiros, 38 Km; M’Boi Mirim, 25 Km; na região Leste: Cidade Tiradentes, $29 \mathrm{Km}$; Guaianases, $28 \mathrm{Km}$. Disponível em: http://www.adistanciaentre.com. Acesso em: 21 jan. 2019.

${ }^{10}$ Para dados do refúgio no Brasil, ver documento do CONARE - Comitê Nacional para os Refugiados. Disponível em: http://www.acnur.org/fileadmin/scripts/doc.php?file=fileadmin/Documentos/portugues/ Estatisticas/Sistema_de_Refugio_brasileiro_-_Refugio_em_numeros_-_05_05_2016. Acesso em: 21 jan. 2019. Ver também relatório do CRAI - Centro de Referência e Acolhida para Imigrantes da Prefeitura de São Paulo. Relatório 2014-2015. Disponível em:

http://www.prefeitura.sp.gov.br/cidade/secretarias/upload/direitos_humanos/Relatorio\%20Anual\%20 CRAI.pdf. Ver também https://www.geledes.org.br/no-centro-de-sao-paulo-surge-uma-pequena-africa/.
} 


\section{Fontes primárias}

ARQUIVO PÚBLICO DO ESTADO DE SÃO PAULO (APESP). CO 5216 - Relação nominal dos africanos livres da Fábrica de Ferro Sáo Joáo de Ipanema, 1851.

ARQUIVO PÚBLICO DO ESTADO DE SÃO PAULO (APESP). CO 5451 - Relação nominal dos africanos livres remetidos da Casa de Correção para a Província de São Paulo, 1851.

ARQUIVO PÚBLICO DO ESTADO DE SÃO PAULO (APESP). EO 1487 - Matrícula de africanos emancipados, 1864.

BRUNO, Ernani da Silva. História e tradiçôes da cidade de São Paulo, v. II Burgo de Estudantes (1828-1872). São Paulo: Livraria José Olympio Ed., 1954.

CEERT - Centro de Estudos das Relaçôes de Trabalho e Desigualdades. Disponível em: http://www.ceert.org.br/noticias/dados-estatisticas/9503/levantamento-mostradistribuicao-da-populacao-negra-em-sao-paulo. Acesso em: 21 jan. 2019.

CONARE - Comitê Nacional para os Refugiados. Disponível em: http://www.acnur.org/ fileadmin/scripts/doc.php?file=fileadmin/Documentos/portugues/Estatisticas/Sistema_de_ Refugio_brasileiro_-_Refugio_em_numeros_-_05_05_2016. Acesso em: 21 jan. 2019.

CRAI - Centro de Referência e Acolhida para Imigrantes da Prefeitura de São Paulo. Relatório 2014-2015. Disponível em: http://www.prefeitura.sp.gov.br/cidade/secretarias/ upload/direitos_humanos/Relatorio\%20Anual\%20CRAI.pdf. Acesso em: 21 jan. 2019.

FREITAS, Affonso de. Tradições e reminiscências paulistanas. Belo Horizonte/São Paulo: Itatiaia/Edusp, 1985.

IBGE - Instituto Brasileiro de Geografia e Estatística. Censo 2010. Disponível em http:// produtos.seade.gov.br/produtos/retratosdesp/view/index.php?temaId=1\&indId=5\&locId= 3550308\&busca $=$

MARTINS, Antonio Egydio. São Paulo Antigo. 1554 a 1910. São Paulo: Paz e Terra, 2003. MORSE, Richard. De comunidade a metrópole: biografia de São Paulo. São Paulo: Comissão do IV Centenário da Cidade de Sáo Paulo, 1954.

MARCÍLIO, Maria Luiza. Crescimento demográfico e evolução agrária paulista. 1700-1836. São Paulo, Hucitec/Edusp, 2000.

MARCÍlIO, Maria Luiza. A cidade de São Paulo. Povoamento e população. 1750-1850. São Paulo: Pioneira, 1974.

TAUNAY, Affonso de E. História da cidade de São Paulo. Brasília: Senado Federal, Conselho Editorial, 2004. 


\section{Referências}

ARAÚJO, Maria L. V. Os caminhos da riqueza dos paulistanos na primeira metade do oitocentos. São Paulo: Hucitec/Fapesp, 2006.

AZEVEDO, Elciene. O direito dos escravos. Lutas juridicas e abolicionismo na província de São Paulo. São Paulo: Unicamp, 2010.

BARTH, Fredrik. Los grupos étnicos e sus fronteras. México: Fondo de Cultura Económica, 1976.

BAZZANEZI, M. S. C. B. (org.) São Paulo do passado. Dados demográficos 1836 (I). Nepo, Unicamp, 1998.

BERTIN, Enidelce. Alforrias na São Paulo do século XIX: liberdade e dominação. São Paulo: Humanitas/FFLCH-USP, 2004.

BERTIN, Enidelce. Os meias-caras. Africanos livres em São Paulo no século XIX. Salto (SP): Schoba, 2013.

BLAJ, Ilana. Mentalidade e sociedade: revisitando a historiografia sobre São Paulo colonial. Revista de História, n. 142-143, 2000.

BREFE, Ana C. F. História Nacional em São Paulo: o Museu Paulista em 1922. Anais do Museu Paulista. São Paulo, n. sér. v. 10/11, p. 79-103, 2002-2003.

DIAS, Maria Odila Leite da Silva. Quotidiano e poder em São Paulo no século XIX. São Paulo: Brasiliense, 1995.

DOMINGUES, Petrônio. Uma história não contada: negro, racismo e branqueamento em São Paulo pós abolição. São Paulo: Senac, 2004.

FARIAS, Juliana B.; SOARES, Carlos E. L; GOMES, Flávio dos S. No labirinto das naçôes: africanos e identidades no Rio de Janeiro. Rio de Janeiro: Arquivo Nacional, 2005.

LUNA, F. V. e KLEIN, H. Evolução da sociedade e economia escravista de São Paulo, de 1750 a 1850. São Paulo: Edusp, 2005.

LUNA, Francisco V., COSTA, Iraci del Nero, KLEIN, Herbert S. Escravismo em São Paulo e Minas Gerais. São Paulo: Imprensa Oficial, 2009.

MARCONDES, Renato L.; MOTTA, José F. As viagens do Conceição Esperança: tráfico de escravos entre São Paulo e Moçambique (1820-22). Resgate - Rev. Interdisciplinar de Cultura, Campinas, v. 25, n. 2 [34], p. 27-56, jul./dez. 2017.

MATTOS, Regiane A. De cassange, mina, benguela a gentio da Guiné. Grupos étnicos e formação de identidades africanas na cidade de São Paulo (1800-1850). Dissertação (Mestrado em História) - FFLCH, Universidade de São Paulo, São Paulo, 2006.

MEDICCI, Ana Paula. Entre a "decadência" e o "florescimento": capitania de São Paulo na interpretação de memorialistas e autoridades públicas (1782/1822). Dissertação (Mestrado 
em História) - FFLCH, Universidade de São Paulo, São Paulo, 2005.

ROLNIK, Raquel. Territórios negros nas cidades brasileiras (etnicidade e cidade em São Paulo e Rio de Janeiro). Estudos Afro-asiáticos, n. 17, p. 29-41, 1989.

SCHWARCZ, Lilia M. O espetáculo das raças. Cientistas, instituiçôes e questão racial no Brasil 1870-1930. São Paulo: Companhia das Letras, 1993.

SCARANO, Julita. Devoção e escravidão: a irmandade de Nossa Senhora do Rosário dos Homens Pretos no Distrito Diamantino no século XVIII. São Paulo: Cia Ed. Nacional, 1978.

SEVCENKO, Nicolau. A cidade metástasis e o urbanismo inflacionário: incursóes na entropia paulista. Revista USP, São Paulo, n. 63, p. 16-35, set./nov., 2004.

SILVA, Rodrigo da. Sobre taipas e textos: um estudo sobre as narrativas a respeito da história de São Paulo - 1772-1953. Dissertação (Mestrado em História) - FFLCH, Universidade de São Paulo, São Paulo, 2009.

WISSENBACH, Maria C. C. Sonhos africanos, vivências ladinas. Escravos e forros em São Paulo (1850-1888). São Paulo: Hucitec/USP, 1998. 